\title{
Side-effects to Antibiotics in Cystic Fibrosis: Dental Changes in Relation to Antibiotic Administration
}

\author{
J. N. SWALLOW*, JACQUELINE DE HALLER, and WINIFRED F. YOUNG \\ From the Department of Child Dental Health, London Hospital Dental Institute, and Queen Elizabeth Hospital \\ for Children, London
}

A discoloration of the primary and permanent dentitions associated with the administration of tetracycline antibiotics to children suffering from cystic fibrosis has been widely reported. The present investigation was carried out at Queen Elizabeth Hospital for Children, London, in an attempt to correlate certain dental findings with the type of tetracycline administered and the severity of the underlying disease.

In recent years at this hospital (Young, 1964) long courses of tetracycline, or its derivatives, in full dosage were given as the drug of choice to children with cystic fibrosis who had, or were suspected of having, a Staphylococcus pyogenes infection during and following episodes of lower respiratory infection. It was valued as a broad-spectrum antibiotic with minimal side-effects, and was used, except in those with evidence of infection resistant to it, in all cases judged to need antibiotic therapy. Latterly, other suitable antibiotics have become available, and they have often been chosen as drugs of choice in place of the tetracyclines. The prevalence of dental sideeffects to the tetracyclines presented here has strengthened the preference for these alternatives.

\section{Material and Methods}

The study comprised 80 children suffering from cystic fibrosis who were attending the hospital regularly for supervision of their treatment. 63 children were selected for dental examination, mainly on the grounds of availability. The teeth were examined under artificial light for the presence of caries and periodontal disease. No probe was used for this examination. The upper and lower incisors were compared with 30 artificial teeth ranging in colour from very light yellow to a dark greybrown. The artificial tooth which most closely resembled the colour of the natural incisors was considered as representing the shade of the individual's teeth and was so recorded. The room was then darkened and the

\footnotetext{
Received September 14, 1966.

* Present address: The Welsh National School of Medicine, Dental School, Heath, Cardiff.
}

teeth illuminated with ultra-violet light from a standard Wood's lamp. The incisor teeth were examined for the presence of a yellow fluorescence.

\section{Standards}

Severity index. The 30 artificial teeth were arranged in order from the lightest to the darkest. Three experienced dental surgeons then divided the 30 teeth into 6 groups, A being the most severely discoloured to $F$ representing those teeth not appreciably discoloured. Because of the small numbers in each group, it was decided to pool $A$ and $B, C$ and $D$, and $E$ and $F$, in order to facilitate analysis. These pooled groups contained: (1) severely discoloured; (2) moderately discoloured; and (3) minimally discoloured teeth. It was realized that the third group included children without any discoloration, but this was felt desirable as the range of normality of tooth coloration has not been accurately determined.

\section{Calculation of tetracycline dosages}

Total dosage. In the majority of patients the total amount of tetracycline prescribed was well documented, as was the type of tetracycline administered. These results are given in Table $I$.

Dosage during tooth formation. Tetracyclines are deposited in the enamel and dentine during calcification, and the tetracyclines in the dentine are largely responsible for the observed discoloration (Owen, 1963). It was decided to calculate the dosage during the calcification of the tooth crown, using widely accepted standards (Massler and Schour, 1944). For the primary incisors it was the amount of tetracycline administered between birth and 1 year. The total amount of tetracycline prescribed during the period of 6 months to 5 years was regarded as being the amount of tetracycline received during calcification of the permanent incisors. The dates of crown completion were slightly modified by the findings of Frankel and Hawes (1964). In view of their work, it was also decided to calculate dosage during an alternative period for the permanent teeth, and this was the total amount of tetracycline prescribed during the period of 6 months to 2 years.

Radiological severity of disease. Cases are grouped according to the radiological severity of their 
TABLE I

Dental Findings in Children With Cystic Fibrosis of the Pancreas

\begin{tabular}{|c|c|c|c|c|c|c|c|c|c|c|}
\hline \multirow{2}{*}{$\begin{array}{l}\text { Age at } \\
\text { Exami- } \\
\text { nation }\end{array}$} & \multirow{2}{*}{$\begin{array}{l}\text { Type of } \\
\text { Tetra- } \\
\text { cycline }\end{array}$} & \multirow{2}{*}{$\begin{array}{c}\text { Total } \\
\text { Dosage } \\
(\mathrm{g} .)\end{array}$} & \multicolumn{2}{|c|}{$\begin{array}{l}\text { Drug and Dosage During } \\
\text { Tooth Formation (g.) }\end{array}$} & \multicolumn{2}{|c|}{ Severity Index $\ddagger$} & \multirow{2}{*}{$\begin{array}{l}\text { Fluores- } \\
\text { cence } \$\end{array}$} & \multirow{2}{*}{$\mathrm{DMF}^{\star \star}$} & \multirow{2}{*}{$d m f \star \star$} & \multirow{2}{*}{ Grouptt } \\
\hline & & & $\begin{array}{c}\text { Prim: 0-1 yr. } \\
\text { Perm: } 6 \text { mth.- } \\
5 \text { yr. }\end{array}$ & $\begin{array}{l}\text { Perm: } 6 \text { mth.- } \\
2 \text { yr. }\end{array}$ & $\begin{array}{l}\text { Perma- } \\
\text { nent } \\
\text { Incisors }\end{array}$ & $\begin{array}{l}\text { Primary } \\
\text { Incisors }\end{array}$ & & & & \\
\hline
\end{tabular}

Findings in Boys

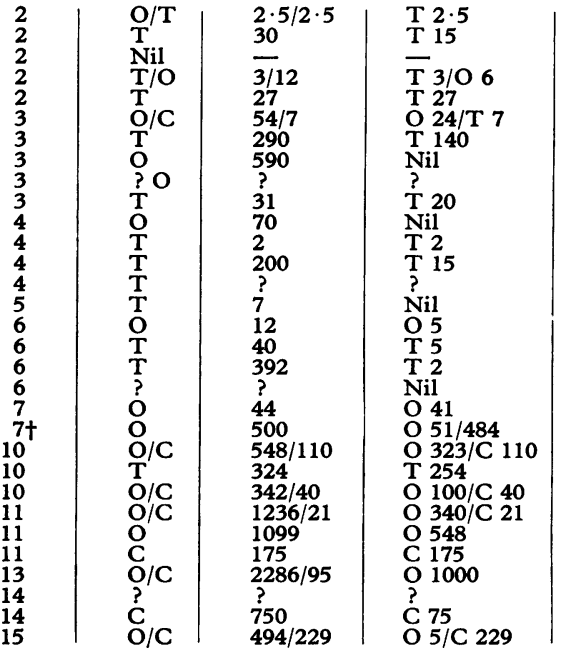

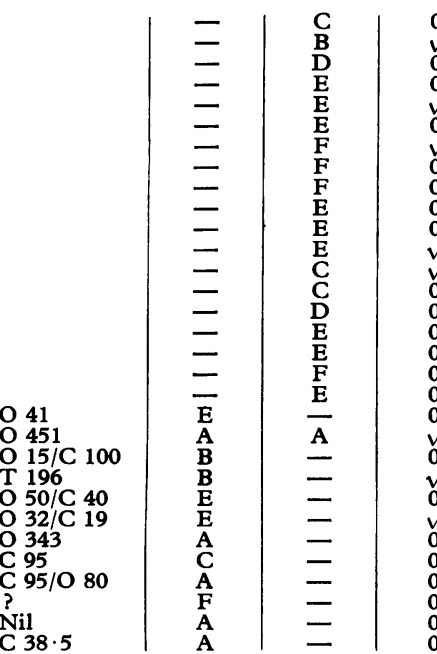
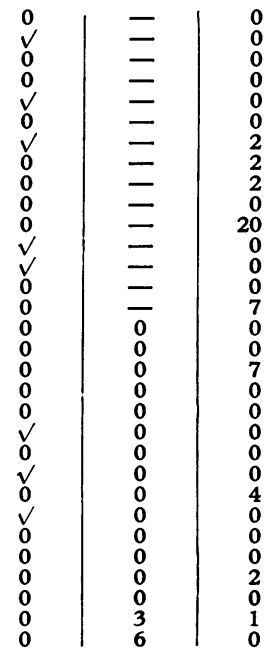

I
I
I
I
I
III
III
III
I
I
I
II
I
I
I
I
I
I
II
I
I
III
III
II
II
II
III
II

Findings in Girls

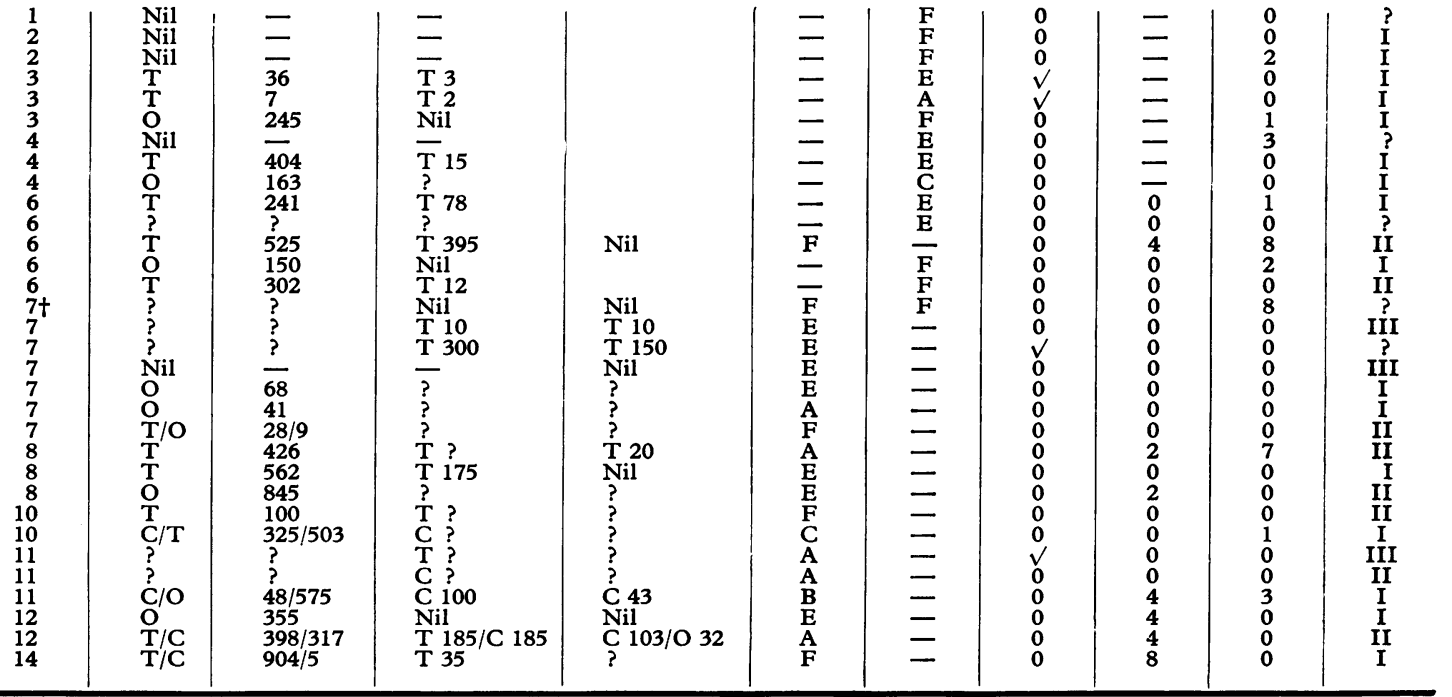

* Type of tetracycline: $\mathrm{T}$-tetracycline; $\mathrm{O}-$ oxytetracycline; $\mathrm{C}-$ chlortetracycline.

Feverity index: A B - severely discoloured; C, D-moderately discoloured; E, F-minimally discoloured.

Fluorescence: $\mathrm{C}$-characteristic bright yellow under ultra-violet light; 0 - no fluorescence.

$\star \star \mathrm{DMF}$ - number of decayed, missing, and filled permanent teeth; dmf-number of decayed, missing and filled primary teeth.

t† Group-radiological severity of the disease: I-no evidence of permanent lung damage; II-minimal localized areas of damage; and III-multiple areas of shadowing which persist in serial films. 
TABLE II

Number of Children With Discoloured Teeth

\begin{tabular}{|c|c|c|c|c|c|c|c|c|c|}
\hline & & & & & & & Primary Incisors & Permanent Incisors & Both \\
\hline $\begin{array}{l}\text { Severe } \\
\text { Moder } \\
\text { Minim }\end{array}$ & $\begin{array}{l}\text { disce } \\
\text { ely d } \\
\text { y di }\end{array}$ & $\begin{array}{l}\text { ured } \\
\text { oloured } \\
\text { loured }\end{array}$ & $\because$ & $\begin{array}{l}\cdots \\
\cdots\end{array}$ & $\begin{array}{l}\cdots \\
\cdots \\
\end{array}$ & $\begin{array}{l}\ddot{*} \\
\cdots\end{array}$ & $\begin{array}{c}3(8 \cdot 8 \%) \\
6(17 \cdot 7 \%) \\
25(73 \cdot 5 \%)\end{array}$ & $\begin{array}{c}13(41 \cdot 9 \%) \\
2(6 \cdot 5 \%) \\
16(51 \cdot 6 \%)\end{array}$ & $\begin{array}{r}15(23.9 \%) \\
8(12.7 \%) \\
40(63.4 \%) \\
\end{array}$ \\
\hline Total & . & . & $\ldots$ & $\ldots$ & . & $\cdots$ & $34(100 \%)$ & $31(100 \%)$ & $63(100 \%)$ \\
\hline
\end{tabular}

TABLE IIIA

Number of Children With Incisors Exhibiting Characteristic Fluorescence Under Ultra-violet Light

\begin{tabular}{|c|c|c|c|c|c|}
\hline & & & Primary Incisors & Permanent Incisors & Both \\
\hline $\begin{array}{l}\text { Severely discoloured } \\
\text { Moderately discoloured } . \text {.. } \\
\text { Minimally discoloured } \ldots\end{array}$ & $\begin{array}{l}\cdots \\
\ddot{*}\end{array}$ & $\begin{array}{ll}\cdots & \cdots \\
\cdots & \cdots\end{array}$ & $\begin{array}{l}3 \\
1 \\
4\end{array}$ & $\begin{array}{l}3 \\
0 \\
2\end{array}$ & $\begin{array}{l}5 \\
1 \\
6\end{array}$ \\
\hline
\end{tabular}

TABLE IIIB

Number of Children Who Received Various Types of Tetracycline and Whose Incisors Exhibited Characteristic Fluorescence Under Ultra-violet Light

\begin{tabular}{|c|c|c|c|c|c|c|c|}
\hline & & & Oxytetracycline & Tetracycline & Chlortetracycline & Mixed & No Tetracyclines \\
\hline $\begin{array}{l}\text { With fluorescence } \\
\text { Without fluorescence }\end{array}$ & $\therefore$ & $\ddot{\cdots}$ & $\begin{array}{c}1(9 \%) \\
10(91 \%)\end{array}$ & $\begin{array}{l}10(40 \%) \\
15(60 \%)\end{array}$ & $\begin{array}{l}0(0 \%) \\
5(100 \%)\end{array}$ & $\begin{array}{l}1(13 \%) \\
7(87 \%)\end{array}$ & $\begin{array}{l}0(0 \%) \\
6(100 \%)\end{array}$ \\
\hline Total & . & $\cdots$ & $11(100 \%)$ & $25(100 \%)$ & $5(100 \%)$ & $8(100 \%)$ & $6(100 \%)$ \\
\hline
\end{tabular}

disease. Those in Group I have no evidence of permanent lung damage; those in Group II have minimal localized areas of damage; and those in Group III have multiple areas of shadowing which persist in serial films (Keith, de Haller, and Young, 1966).

\section{Results}

The findings on the children examined are given in Table I. It should be noted that two children had both primary and permanent incisors present, and this explains the apparent disparity in totals in the subsequent tables.

Prevalence of discoloured teeth. Fifteen (24\%) of the children had incisors that were classified as being severely discoloured, $8(13 \%)$ had incisors that were moderately discoloured, and $40(63 \%)$ had incisors that were minimally discoloured. Table II shows the number of children with discoloured primary and permanent teeth. It will be seen that proportionately more permanent teeth were graded severely discoloured than primary teeth $\left(\chi^{2}=8 \cdot 37\right.$ 2 d. of f.; $p<0.01>0.001$ ).

Presence of fluorescence. Twelve (19\%) children had incisors which fluoresced bright yellow under the ultra-violet light. Of these 12 children, 5 had teeth graded severely discoloured, 1 moderately discoloured, and 6 minimally discoloured. Information was available on the type of drug taken at any time in 55 of the 63 children. It will be noted that proportionately more children who had received tetracycline had incisors which fluoresced in the characteristic manner than the children who had received oxytetracycline, chlortetracycline, or a mixture of these drugs (Table III).

Prevalence of dental caries. The dmf (total number of decayed, missing, and filled primary teeth) and the DMF (total number of decayed, missing, and filled permanent teeth) for each child are given in Table I and plotted in the Figure. The number of children examined was too small to draw any firm conclusions as to whether their caries experience was high, average, or low compared with other children. However, in the Figure the average figures per year of age for either sex are plotted against average figures for 1500 physically handicapped children, attending day schools, who were examined at the same time using similar methods. It will be seen that there is a tendency for the caries experience of the children with cystic fibrosis to be lower than that of the physically handicapped 


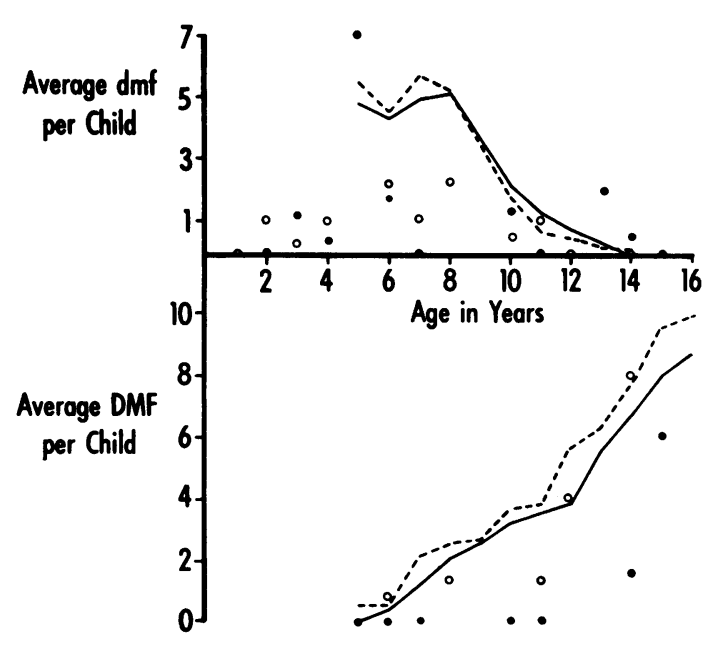

-...- Physically handicapped girls at day schools

- Physically " boys. . .

- Girls with cystic fibrosis

- Boys - - -

FIG.-Dental caries prevalence in children with cystic fibrosis.

children, though no definite conclusions can be drawn from this.

Only 1 child of the 63 seen had any form of hypoplasia of the teeth. This was a 12-year-old girl who had linear striations on the upper and lower permanent incisors.
Gingivitis was also very rare. Only 2 children examined were felt to have any form of gingivitis: one had a mild marginal gingivitis, the other a more severe gingival infection. 6 of the children examined had supragingival calculus, which fluoresced a bright orange colour under ultraviolet light.

Type of tetracycline and severity of tooth discoloration. Table IV shows the number of patients who received, at any time, the various types of tetracycline and indicates the severity of tooth discoloration. This information was available on 55 children. The relation between the type of tetracycline and the severity of the staining was similar in both the primary and permanent dentitions. Children who received chlortetracycline and oxytetracycline had proportionately more severely discoloured teeth than children who received tetracycline or a mixture of the tetracyclines. However, if one compares the number of children with severely and moderately discoloured teeth, who took oxytetracycline, with those who took tetracycline, there is no association between the types of drug taken and the severity of staining $\left(\chi^{2}=1.97\right.$ 1 d. of $f$; $p>0.05$ ).

Six children had no tetracycline therapy. Only one of these was thought to have moderately discoloured teeth, the others having minimally discoloured teeth.

Relation between type, and dosage of tetracycline, and severity of tooth discoloration.

Total dosage. The total dosage and type of tetracycline were known for 53 children. Table $\mathrm{V}$ gives the mean total dosages and range, together with

TABLE IV

Number of Children Who Received the Types of Tetracycline and the Severity of their Tooth Discoloration

\begin{tabular}{|c|c|c|c|c|c|c|c|c|c|}
\hline & & & & \multicolumn{2}{|c|}{ Severely Discoloured } & \multicolumn{2}{|c|}{ Moderately Discoloured } & \multicolumn{2}{|r|}{ Minimally Discoloured } \\
\hline $\begin{array}{l}\text { Primary Incisors } \\
\text { Oxytetracycline } \\
\text { Tetracycline } \\
\text { Chhortetracycline } \\
\text { Mixed ... } \\
\text { No tetracyclines }\end{array}$ & $\begin{array}{l}\cdots \\
\because \\
\cdots \\
\cdots\end{array}$ & $\begin{array}{l}\because \\
\because \\
\cdots \\
\cdots\end{array}$ & $\begin{array}{l}\because \\
\because \\
\because \\
\cdots\end{array}$ & \multicolumn{2}{|c|}{$\begin{array}{l}1 \\
2 \\
0 \\
0 \\
0\end{array}$} & \multicolumn{2}{|r|}{$\begin{array}{l}1 \\
4 \\
0 \\
0 \\
1\end{array}$} & \multicolumn{2}{|r|}{$\begin{array}{r}2 \\
10 \\
0 \\
2 \\
4\end{array}$} \\
\hline $\begin{array}{c}\text { Permanent Incisors } \\
\text { Oxytetracycline } \\
\text { Tetracycline } \\
\text { Chlortetracycline } \\
\text { Mixed ... } \\
\text { No tetracyclines }\end{array}$ & $\begin{array}{l}\because \\
\because \\
\because \\
\therefore\end{array}$ & $\begin{array}{l}\because \\
\because \\
\cdots \\
\cdots\end{array}$ & $\begin{array}{l}\cdots \\
\cdots \\
\cdots \\
\cdots\end{array}$ & \multicolumn{2}{|c|}{$\begin{array}{l}4 \\
3 \\
3 \\
3 \\
0\end{array}$} & & $\begin{array}{l}0 \\
0 \\
2 \\
0 \\
0\end{array}$ & \multicolumn{2}{|r|}{$\begin{array}{l}4 \\
6 \\
0 \\
3 \\
1\end{array}$} \\
\hline \multicolumn{3}{|c|}{ Both Dentitions } & \multicolumn{2}{|c|}{ No. of Children } & \multicolumn{2}{|c|}{ Severely Discoloured } & \multicolumn{2}{|c|}{ Moderately Discoloured } & Minimally Discoloured \\
\hline $\begin{array}{ll}\text { Oxytetracycline } & \ldots \\
\text { Tetracycline } & \ldots \\
\text { Chlortetracycline } & \ldots \\
\text { Mixed } & \ldots \\
\text { No tetracyclines } & \ldots\end{array}$ & $\begin{array}{l}\ldots \\
\because \\
\cdots\end{array}$ & $\begin{array}{r}. . \\
\cdots \\
. \\
.\end{array}$ & \multicolumn{2}{|c|}{$\begin{array}{l}11(100 \%) \\
25(100 \%) \\
5(100 \%) \\
8(100 \%) \\
6(100 \%)\end{array}$} & \multicolumn{2}{|c|}{$\begin{array}{l}4(41 \cdot 7 \%) \\
5(20 \%) \\
3(60 \%) \\
3(37 \cdot 5 \%) \\
0(0 \%)\end{array}$} & \multicolumn{2}{|l|}{$\begin{array}{l}1(8 \cdot 3 \%) \\
4(16 \%) \\
2(40 \%) \\
0(0 \%) \\
1(16 \cdot 7 \%)\end{array}$} & $\begin{array}{c}6(50 \%) \\
16(64 \%) \\
0(0 \%) \\
5(62 \cdot 5 \%) \\
5(83 \cdot 3 \%)\end{array}$ \\
\hline
\end{tabular}


TABLE V

Type of Tetracycline, Total Dosage (g.), and Severity of Tooth Discoloration

\begin{tabular}{|c|c|c|c|c|c|c|c|}
\hline \multirow{2}{*}{ Type of Tetracycline } & \multicolumn{3}{|c|}{ Primary Incisors } & \multicolumn{3}{|c|}{ Permanent Incisors } & \multirow{2}{*}{ Severity Index } \\
\hline & $\begin{array}{l}\text { No. of } \\
\text { Children }\end{array}$ & $\begin{array}{l}\text { Mean } \\
\text { Dosage }\end{array}$ & Range & $\begin{array}{l}\text { No. of } \\
\text { Children }\end{array}$ & $\begin{array}{l}\text { Mean } \\
\text { Dosage }\end{array}$ & Range & \\
\hline Oxytetracycline & $\begin{array}{l}1 \\
1 \\
5\end{array}$ & $\begin{array}{l}500 \\
163 \\
213 \cdot 4\end{array}$ & $\overline{-}$ & $\frac{3}{4}$ & $\begin{array}{l}546 \cdot 6 \\
328\end{array}$ & $\begin{array}{l}41-1099 \\
44-845\end{array}$ & $\begin{array}{l}\text { Sev. discoloured } \\
\text { Mod. discoloured } \\
\text { Min. discoloured }\end{array}$ \\
\hline Tetracycline $\quad \ldots$ & $\begin{array}{r}2 \\
2 \\
10\end{array}$ & $\begin{array}{r}18 \cdot 5 \\
103 \cdot 5 \\
176 \cdot 5\end{array}$ & $\begin{array}{l}7-30 \\
7-200 \\
2-404\end{array}$ & $\frac{2}{3}$ & $\frac{375}{395 \cdot 7}$ & $\begin{array}{l}324-426 \\
100-562\end{array}$ & $\begin{array}{l}\text { Sev. discoloured } \\
\text { Mod. discoloured } \\
\text { Min. discoloured }\end{array}$ \\
\hline Chlortetracycline & E & 二 & 二 & $\begin{array}{l}1 \\
1\end{array}$ & $\begin{array}{r}750 \\
175 \\
\end{array}$ & 二 & $\begin{array}{l}\text { Sev. discoloured } \\
\text { Mod. discoloured } \\
\text { Min. discoloured }\end{array}$ \\
\hline Mixed $\ldots \quad \ldots$ & $\overline{1}$ & $\begin{array}{r}\overline{5} \\
38\end{array}$ & $\overline{15-61}$ & $\begin{array}{l}5 \\
1 \\
4\end{array}$ & $\begin{array}{l}1000 \\
828 \\
646 \cdot 2\end{array}$ & $\begin{array}{c}523-2381 \\
\overline{37-1257}\end{array}$ & $\begin{array}{l}\text { Sev. discoloured } \\
\text { Mod. discoloured } \\
\text { Min. discoloured }\end{array}$ \\
\hline No tetracyclines & $\overline{1}$ & E & 二 & $\overline{1}$ & E & 二 & $\begin{array}{l}\text { Sev. discoloured } \\
\text { Mod. discoloured } \\
\text { Min. discoloured }\end{array}$ \\
\hline
\end{tabular}

the number of children observed, according to the type of drug administered. Although the numbers were small, there was no consistent finding in either the primary or permanent dentitions on the amount of drug taken and the severity of discoloration. There was a slight tendency for children with more severely discoloured teeth to have received a higher dosage of antibiotic, but this was not a consistent finding.

Dosage during tooth formation. Primary incisors: 0-1 year; permanent incisors: 6 months -5 years. The type of drug and the dosage administered during tooth formation in this period were known for 42 children. Table VI shows the severity index compared with the dosage and the range for the various tetracyclines. There was a tendency for the children with the most discoloured teeth to have received the greatest amount of tetracycline, but again this was not a consistent finding for every child. Permanent incisors: 6 months-2 years. The average dosages, together with the range, for 21 children are tabulated as before for the various types of tetracycline and the severity of tooth discoloration. From Table VI, it can be seen that there was no consistent relation between the average amount of

TABLE VI

Type of Tetracycline, Dosage (g.) During Period of Tooth Formation, and Severity of Tooth Discoloration

\begin{tabular}{|c|c|c|c|c|c|c|c|c|c|c|c|}
\hline \multirow{3}{*}{$\begin{array}{c}\text { Type of } \\
\text { Tetracycline }\end{array}$} & & \multirow{2}{*}{\multicolumn{3}{|c|}{$\begin{array}{c}\text { Primary Incisors } \\
\text { Birth-1 Year }\end{array}$}} & \multicolumn{6}{|c|}{ Permanent Incisors } & \multirow{3}{*}{ Severity Index } \\
\hline & & & & & \multicolumn{3}{|c|}{6 Months-5 Years } & \multicolumn{3}{|c|}{6 Months-2 Years } & \\
\hline & & $\begin{array}{l}\text { No. of } \\
\text { Child- }\end{array}$ & $\begin{array}{l}\text { Mean } \\
\text { Dosage }\end{array}$ & Range & $\begin{array}{c}\text { No. of } \\
\text { Child- } \\
\text { ren }\end{array}$ & $\begin{array}{c}\text { Mean } \\
\text { Dosage }\end{array}$ & Range & $\begin{array}{c}\text { No. of } \\
\text { Child- } \\
\text { ren }\end{array}$ & $\begin{array}{l}\text { Mean } \\
\text { Dosage }\end{array}$ & Range & \\
\hline Oxytetracycline & .. & $\frac{1}{2}$ & $\frac{51}{5 \cdot 5}$ & $\overline{\overline{5}}$ & $\frac{2}{1}$ & $\frac{516}{41}$ & $\begin{array}{c}484-584 \\
\text { - }\end{array}$ & $\frac{2}{1}$ & $\frac{397}{41}$ & $\begin{array}{c}343-451 \\
\text { - }\end{array}$ & $\begin{array}{l}\text { Sev. discoloured } \\
\text { Mod. discoloured } \\
\text { Min. discoloured }\end{array}$ \\
\hline Tetracycline & .. & $\begin{array}{c}2 \\
2 \\
11 \\
\end{array}$ & $\begin{array}{r}8 \cdot 5 \\
8 \cdot 8 \\
27 \cdot 9 \\
\end{array}$ & $\begin{array}{c}2-15 \\
2 \cdot 5-15 \\
3-140 \\
\end{array}$ & $\frac{1}{3}$ & $\frac{254}{183}$ & $\overline{10-395}$ & $\frac{2}{2}$ & $\frac{108}{125}$ & $\begin{array}{l}20-196 \\
10-50\end{array}$ & $\begin{array}{l}\text { Sev. discoloured } \\
\text { Mod. discoloured } \\
\text { Min. discoloured }\end{array}$ \\
\hline Chlortetracycline & $\ldots$ & 二 & 二 & 二 & $\begin{array}{l}2 \\
1 \\
\end{array}$ & $\begin{array}{l}87 \cdot 5 \\
175 \\
\end{array}$ & ${ }^{75-100}$ & $\begin{array}{l}2 \\
1 \\
\end{array}$ & $\begin{array}{l}40 \cdot 8 \\
95 \\
\end{array}$ & $\begin{array}{c}38 \cdot 5-43 \\
-\end{array}$ & $\begin{array}{l}\text { Sev. discoloured } \\
\text { Mod. discoloured } \\
\text { Min. discoloured }\end{array}$ \\
\hline Mixed & .. & $\overline{1}$ & $\frac{7}{31}$ & 二 & $\frac{3}{2}$ & $\begin{array}{l}566 \cdot 3 \\
250 \cdot 5\end{array}$ & $\begin{array}{l}234-1095 \\
140-361\end{array}$ & $\frac{3}{2}$ & $\frac{426 \cdot 7}{295}$ & $\begin{array}{l}135-895 \\
51-540\end{array}$ & $\begin{array}{l}\text { Sev. discoloured } \\
\text { Mod. discoloured } \\
\text { Min. discoloured }\end{array}$ \\
\hline No tetracyclines & .. & $\overline{5}$ & 二 & 二 & $\begin{array}{l}-1 \\
3\end{array}$ & 二 & 二 & $\frac{1}{5}$ & 三 & 二 & $\begin{array}{l}\text { Sev. discoloured } \\
\text { Mod. discoloured } \\
\text { Min. discoloured }\end{array}$ \\
\hline
\end{tabular}


TABLE VII

Radiological Severity of Disease, Severity of Tooth Discoloration, and Number of Children Affected (Primary and Permanent Dentitions Combined)

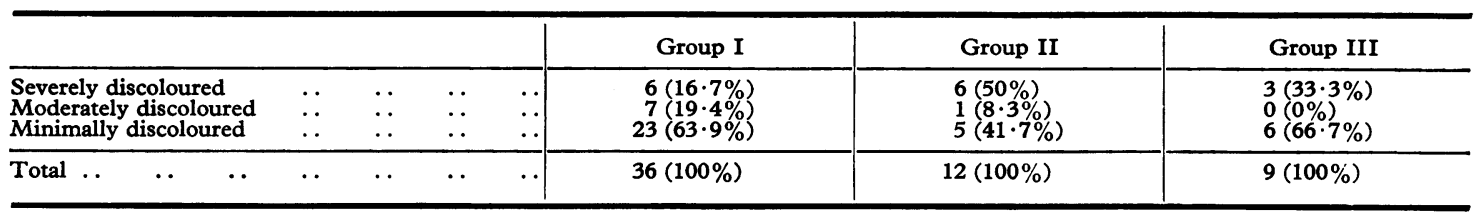

drug taken and the degree of tooth discoloration.

Radiological severity of disease and severity of tooth discoloration. Table VII summarizes the findings on the children who were grouped according to the radiological severity of their disease and the severity of their tooth discoloration. Although there was some tendency for the children in Groups II and III to have proportionately more severely discoloured teeth than the children in Group I, when the children with severely and moderately discoloured teeth are pooled and compared with those with minimally discoloured teeth, there is no significant association $\left(\chi^{2}=2.062 \mathrm{~d}\right.$. of $f . ; p>0.05)$. It should be noted that the data in this Table relate to both the primary and the permanent dentitions.

\section{Discussion}

Shwachman, Fekete, Kulczycki, and Foley (1958-59) described the presence of pigmented teeth in children with cystic fibrosis, who had received tetracyclines as part of their treatment. The presence of discoloured teeth in children with this disease has also been described by Zegarelli, Denning, Kutscher, Tuoti, and di Sant'Agnese (1960, 1961), Zegarelli, Kutscher, Denning, Saporito, Slaughter, and Fahn (1962), Zegarelli, Denning, Kutscher, Fahn, Kirschner, and Slaughter (1963b), and by Sullivan (1963). It is now clear that the discoloration of teeth found in children with cystic fibrosis is not a sign of the disease, but is the result of the intake of tetracyclines during the formation of the teeth. Incriminated are four main types of tetracyclines: tetracycline, oxytetracycline, chlortetracycline, and demethylchlortetracycline. The literature on the various effects of these drugs has been reviewed thoroughly by Johnson (1964), and their effect on the teeth has been discussed in a leading article (Lancet, 1966). Initially, it was felt (Wallman and Hilton, 1962a) that a bright yellow fluorescence was diagnostic of the presence of tetracycline in the teeth, but it is now generally believed that this phenomenon is eliminated or considerably reduced by exposure to light (Storey, 1963). In the work on the effects of tetracycline on the teeth there are three main areas which have produced controversy. These are: (1) the degree of discoloration related to the type of tetracycline administered; (2) the association of hypoplastic defects with tetracycline therapy; and (3) the effect of tetracycline therapy on the caries prevalence.

Type of tetracycline and degree of discoloration. Wallman and Hilton (1962a) believed that tetracycline produced a more severe discoloration than oxytetracycline, a view supported by Weyman (1965). The latter felt that there was a remarkable correspondence with the type of tetracycline and the colour of the teeth. Those who had received tetracycline had yellow teeth, those who had received chlortetracycline had grey-brown teeth. She concluded that oxytetracycline probably produced less staining than the other types of drugs. Ibsen, Urist, Sognnaes, and Keen (1965), working with New Zealand rabbits, concluded that tetracycline and demethylchlortetracycline discoloured teeth to a greater extent than chlortetracycline and oxytetracycline, chlortetracycline producing very little staining either before or after exposure to light. Owen (1963) similarly found in dogs that chlortetracycline did not stain teeth. The children with cystic fibrosis, reported by Shwachman et al. (1958-59), had received large doses of chlortetracycline, though some had also received oxytetracycline and tetracycline to a lesser degree.

The reason for these different findings cannot be easily explained. It may well be that the staining produced by tetracyclines in the experimental animal is not comparable to the staining produced in man. The present work does not clarify the matter either. No great differences were observed in children who had received any of the forms of tetracycline, but it should be pointed out that matching the colour of teeth with a shade guide is largely subjective-what appears a dark green- 
brown to one observer may well seem orange to another.

The dosage level has been described as being critical. Bevelander and Nakahara (1966) cite Pindborg in believing that it is not so much the duration of the treatment that is important as the total dosage of the drug administered, and they supported this with experiments with the white rat. The present survey does not seem to support the view that the total dosage is the important factor. However, it does give further weight to the belief of Zegarelli, Denning, Kutscher, Fahn, and Kirschner (1963a) that there is no striking relation between the coloration of the patients' teeth and the severity of their illness.

Few children receive as much tetracycline as have those in this series, the majority of whom have had extensive courses of the drug over periods of months and sometimes years. Whereas in animals and adults, receiving a short course, it might be possible to measure quantitatively the amount of staining produced and relate it to the drug dosage, in children with cystic fibrosis this is hardly a practicable proposition. It is also possible that the disease itself might modify the uptake of the tetracycline, a view advanced by Zegarelli et al. (1963a, b).

Association of hypoplastic defects with tetracycline therapy. Wallman and Hilton $(1962 a, b)$ believed that the observed enamel hypoplasia was caused by the tetracycline drugs rather than by the disease being treated, a view supported by Witkop and Wolf (1963). Harcourt, Johnson, and Storey (1962) also found that some teeth from children who had received large doses of tetracycline had hypoplastic enamel, but they felt that this was due to the metabolic upsets.

In the present study macroscopic defects were noted in only one patient. However, this does not mean that a microscopical examination of the teeth would not have revealed the presence of a disturbance of mineralization either in the dentine or in the enamel.

Effect of tetracycline therapy on caries prevalence. Because of the interest in the bacteriological aspects of dental caries and the possibilities of caries prevention by the use of antibiotics, there have been several reports on the relation between caries prevalence and tetracycline therapy. Bevelander and Nakahara (1966) interpreted Wallman and Hilton (1962a) as believing that the teeth that demonstrated tetracycline discoloration were highly susceptible to caries. On the other hand, Weyman and Porteous (1963) claimed that the caries incidence was normal in a group of children who had received tetracyclines. Surprisingly little reference has been made to the caries prevalence in children with cystic fibrosis. H. M. Kopel (personal communication, 1966) believes, from a clinical observation, that the teeth of these children are less susceptible to caries, and the present material seems to lend weight to this belief. Although the numbers were small, the trend was for the children to have a lower caries prevalence. It might be argued that the discoloration produced by the tetracyclines masks any colour changes produced by caries and thus makes identification of this disease difficult. However, in children of a wide age range, such as in the present survey, it would be reasonable to suppose that any masking effect would be lost, since there would be a visible breakdown of the tooth substance as the caries process advanced.

\section{Summary and Conclusions}

Dental examinations were carried out on 63 children suffering from cystic fibrosis. $36.5 \%$ of the children had appreciably discoloured teeth. No firm relation could be established between the type of tetracycline administered and the degree of discoloration, the radiographic severity of the cystic fibrosis, or the severity of respiratory infection. Neither could a relation be demonstrated between the total dosage and the severity of tooth discoloration, nor the dosage estimated as being taken during tooth formation. The incisor teeth of children who had received tetracycline showed considerably more characteristic fluorescence under ultraviolet light than those of children who had received other forms of the drug.

The present report substantiates the findings of other workers, that children with cystic fibrosis, who are receiving tetracycline therapy, are liable to have discoloured teeth. However, the relatively small number of children examined means that many questions remain unanswered, particularly the effect of the various tetracyclines on the type of discoloration produced and at what stage of tooth development the tetracyclines produce discoloration. More objective assessments of the effect of tetracycline therapy on the teeth will have to be made before these questions can be answered. It is apparent that children receiving large doses of tetracycline are liable to have disfiguring staining of the teeth and, if alternative antibiotics are available which do not belong to the tetracycline family, these should be employed instead.

We wish to express our gratitude to the consultant medical staff of the hospital for referring the cases to us, and to Dr. M. Mearns and Miss V. Ambridge for their 
help in collecting the data, and to Mrs. P. Charlton for secretarial assistance.

\section{REFERENCES}

Bevelander, G., and Nakahara, H. J. (1966). The effect of diverse amounts of tetracycline on fluorescence and coloration of teeth. F. Pediat., 68, 114.

Frankel, M. A., and Hawes, R. R. (1964). Tetracycline antibiotics and tooth discoloration. F. oral Ther., 1, 147.

Harcourt, J. K., Johnson, N. W., and Storey, E. (1962). In vivo incorporation of tetracycline in the teeth of man. Arch. oral Biol., 7, 431.

Ibsen, K. H., Urist, M. R., Sognnaes, R. F., and Keen, J. (1965). Differences among tetracyclines with respect to the staining of teeth. F. Pediat., 67, 459.

Johnson, R. H. (1964). The tetracyclines : a review of the literature1948 through 1963. f. oral Ther., 1, 190.

Keith, C. G., de Haller, J., and Young, W. F. (1966). Side-effects to antibiotics in cystic fibrosis. I. Ocular changes in relation to antibiotic administration and to severity of pulmonary involvement. Arch. Dis. Childh., 41, 262.

Lancet (1966). Tetracyclines and the teeth. 1, 917.

Massler, M., and Schour, I. (1944). Atlas of the Mouth and Adjacent Parts in Health and Disease. Bureau of Public Relations of the American Dental Association, Chicago.

Owen, L. N. (1963). The effects of administering tetracyclines to young dogs with particular references to localization of the drugs in the teeth. Arch. oral Biol., 8, 715.

Shwachman, H., Fekete, E., Kulczycki, L. L., and Foley, G. E. (1958-59). The effect of long term antibiotic therapy in patients with cystic fibrosis of the pancreas. Antibiot. Ann., 692.
Storey, E. (1963). Experimental tetracycline administration. f. dent. Res., 42, 5.

Sullivan, R. E. (1963). Discoloration of the teeth in patients with cystic fibrosis. Dental thesis, Graduate College, University of Nebraska.

Wallman, I. S., and Hilton, H. B. (1962a). Teeth pigmented by tetracycline. Lancet, 1, 827 .

, and - (1962b). Prematurity, tetracycline and oxytetracycline in tooth development. ibid., 2, 720.

Weyman, J. (1965). The clinical appearances of tetracycline staining of the teeth. Brit. dent. F., 118, 289.

- , and Porteous, J. R. (1963). Tetracycline staining of teeth: a report on clinical material. f. dent. Res., 42, 1111.

Witkop, C. J., and Wolf, R. O. (1963). Hypoplasia and intrinsic staining of enamel following tetracycline therapy. f. Amer. med. Ass., 185, 1008.

Young, W. F. (1964). Management. In Cystic Fibrosis, a Symposium, p. 67. Chest and Heart Association, London.

Zegarelli, E. V., Denning, C. R., Kutscher, A. H., Fahn, B., and Kirschner, G. (1963a). Discoloration of teeth in patients with cystic fibrosis of the pancreas : relation to severity of disease. N.Y. St. dent. F., 29, 75.

$-\longrightarrow,-$ and Slaughter, T. W. (1963b). Discoloration of teeth in patients with cystic fibrosis of the pancreas : role of tetracycline therapy. Clin. Pediat. (Philad.), 2, 329.

- - Tuoti, F., and di Sant'Agnese, P. A. (1960) Tooth discoloration in cystic fibrosis. Pediatrics, 26, 1050. ,,$-\frac{1}{\text {, and }}$ (1961). Discoloration of the teeth

report. N.Y. St. dent. F., 27, 237. T. W., and Fahn, B. (1962). Coloration of teeth in patients with cystic fibrosis of the pancreas. Part II. Oral Surg., 15, 929. 